\title{
Prevalence of Type 1 Diabetes and Presence of Optimal Support Services in Public Schools a Case Study of Gweru, Zimbabwe
}

\author{
Miriraishe Chigova and Prosper Chopera* \\ Department of Food, Nutrition and Family Sciences, University of Zimbabwe, Zimbabwe
}

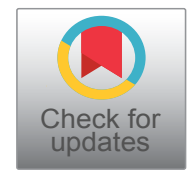

*Corresponding author: Prosper Chopera, Department of Food, Nutrition and Family Sciences, University of Zimbabwe, P.O. Box MP167, Mt Pleasant, Harare, Zimbabwe, Tel: +263-242-303211

\begin{abstract}
Introduction: Type 1 diabetes sometimes referred to as childhood onset diabetes is characterized by deficient hormone insulin production by the body. Children spend most of their time in school such that when there is an imbalance between medication, food and physical activity the wellbeing of the minor is placed at risk. The main objective was to investigate the prevalence of Type 1 diabetes and presence of support services for affected children in public schools in Gweru, Zimbabwe.
\end{abstract}

Methods: A cross-sectional study was conducted in public primary schools in the third largest city of Zimbabwe, Gweru. Key informant interviews were conducted with selected staff members to determine the type of support services available for children with Type 1 diabetes. The Michigan Diabetes Knowledge test was used to collect data from school staff on knowledge about the condition.

Results: The prevalence of Type 1 diabetes was $0.1 \%$ across 21 primary schools assessed. A third of the schools $(33.3 \%)$ offered support services such as insulin administration ( $n=2)$, nutrition support $(n=7)$, and blood glucose monitoring $(n=5)$. The mean knowledge score was $15.4 \pm$ 2.7. Half of the schools scored above the mean knowledge score.

Conclusions: The results show that there was a low but significant prevalence of Type 1 diabetes in Gweru urban primary schools. There are few supportive services being provided in the schools and there is inadequate information and specific school policies pertaining management of Type 1 diabetes in public schools. Intervention from policy makers is warranted.

\section{Keywords}

Type 1 diabetes, Schools, Support service

\section{Introduction}

Type 1 diabetes is a form of diabetes with onset at childhood characterized by deficient hormone insulin production by the body. The body fails to produce insulin due to autoimmune damage of the cells in the pancreas called the beta cells [1]. Typical symptoms include excessive fluid intake, frequent urination, drowsiness, increased appetite, rapid weight loss, abrupt vision change (noticeable often first in the classroom), fruity odor breath, and mood changes causing behavior problems in school. If untreated and or managed well the condition has some immediate complications such as hypoglycemia, hyperglycemia and long term complications such as eye disease (retinopathy), kidney disease (nephropathy) and nerve disease (neuropathy). All these can affect the school child inevitably reducing school attendance, suboptimal class performance and in the long term negative socio-economic consequences [2]. The main goal of management is to maintain glycaemia as close to metabolic normality as possible. A combination of insulin administration, physical activity, diet, blood glucose monitoring and prevention of hypoglycemia and ketoacidosis are the main components of management [3]. Glucose monitoring especially is vital to detect hyper or hypoglycemia in the child before it's too late.

The prevalence of Type 1 diabetes in Zimbabwe is not well known [4] but is estimated to be under $0.1 \%$ $[5,6]$. It is projected to be on the increase $[6,7]$ however data on incidence and prevalence remains scarce in Zimbabwe. Children spend most of their time at school (30-35 hours per week) and hence the importance of

Citation: Chigova M, Chopera P (2020) Prevalence of Type 1 Diabetes and Presence of Optimal Support Services in Public Schools a Case Study of Gweru, Zimbabwe. Int J Diabetes Clin Res 7:125. doi. org/10.23937/2377-3634/1410125

Accepted: June 08, 2020: Published: June 10, 2020

Copyright: (C) 2020 Chigova M, et al. This is an open-access article distributed under the terms of the Creative Commons Attribution License, which permits unrestricted use, distribution, and reproduction in any medium, provided the original author and source are credited. 
personnel entrusted with the child to be involved in management of any condition they may have. The school is a critical environment for children with diabetes. There is dearth of information on the prevalence of optimal support services for Type 1 diabetic children in primary schools in developing countries leading possibly to poor management.

Zimbabwe has a School Health Policy which emphasizes not only the teaching of relevant topics but also the presence of appropriate school health services irrespective of economic status, religious beliefs and ownership of school [8]. Conditions such as those concerning sexual and reproductive health, environment and sanitation are well documented and receive adequate attention in school health policies [8] however Type 1 diabetes an equally important topic is less discussed. Intervention in schools is key as it offers a window of opportunity to educate for behavior change thus preventing lifelong debilitating effects of uncontrolled diabetes in the future of these children [9]. The policy further states that "Institutional capacity shall be strengthened for the support of learners with special needs including diabetes". This level of 'strengthening' has never been evaluated. The main objective of this study was therefore to investigate the prevalence of Type 1 diabetes as well as presence of support services for children with Type 1 diabetes in public schools in Gweru, Zimbabwe.

\section{Methods}

The study was conducted in the third largest city in Zimbabwe, Gweru urban. It is centrally located and has an urban population of 157865 [10]. This was a cross-sectional study in which key teaching and non-teaching staff who work at primary schools and spend most of the time with the learners at school were interviewed. A desk review was conducted of Ministry of Primary and Secondary Education (MOPSE) policies on support services for children with specialized needs in this case diabetes. A list of all the registered primary schools was obtained from MOPSE [11]. Due to the exploratory nature of the study, convenience sampling was used to select 21 urban primary schools that consented out of 97 listed schools. Key informant interviews were then conducted with the School Heads from the selected primary schools. The interview collected data on, the location of the school, the number of staff members trained/untrained in management of diabetes, the number of students who are diagnosed with Type 1 diabetes. The presence/absence of the following support services extracted from previous studies on diabetes care in schools was assessed $[9,12]$ : Presence of people in charge of glucose monitoring in-case it is needed, staff trainings on diabetes management, availability of a school nurse, availability of school diabetes management policies, other support given to diabetic children. A validated diabetes care knowledge test (The Michigan Diabetes Knowledge Test) $[13,14]$ was administered to
2 randomly selected teaching and non teaching staff as these were considered to be in contact with the children on a daily basis. The random selection of the 2 interviewees (I teaching and 1 non teaching) was done using the random function on an excel spreadsheet which had a numbered list of all teaching and non-teaching staff members separately. The test assessed general knowledge of diabetes (definition of diabetes diet, carbohydrate content of different foods, effects of insulin, actions to take during hypo/hyperglycemic events). The Michigan Diabetes Knowledge Test is a 23 item test with one possible answer. The respondents were awarded one point for each correct response. Data capturing and processing were done using SPSS version 20 and MS excel (Microsoft Inc).

\section{Results}

The total number of primary school children in Gweru urban was 24863. Only eight schools out of a total of 21 assessed schools had children with Type 1 diabetes enrolled. The total number of children confirmed using medical records was 26 . The prevalence of Type 1 diabetes was $0.1 \%$. Females $(n=14)$ were slightly more than males $(n=12)$. More than half of the children with diabetes $57 \%$ and $43 \%$ of the males and females respectively required monitoring at school and the rest were independent of glucose monitoring. Only two schools had school nurses and they had been trained about management of diabetes in nursing school. Only 1 school had a written policy. In total $33 \%$ of the schools offered some support service to children with diabetes (Table 1).

Table 1: Characteristics of schools studied.

\begin{tabular}{|l|l|}
\hline Variable & N or \% \\
\hline Number of schools studied & 21 \\
\hline Total children enrolled in studied schools & 24863 \\
\hline Children diagnosed with Type 1 diabetes & 26 \\
\hline Males & 12 \\
\hline Children who require glucose monitoring at school & 14 \\
\hline Total teaching staff employed in the schools & 748 \\
\hline $\begin{array}{l}\text { Total non-teaching staff members employed in the } \\
\text { schools }\end{array}$ & 153 \\
\hline Number of teachers interviewed & 21 \\
\hline Number of non-teaching staff interviewed & 21 \\
\hline Staff trained on management of diabetes & 2 \\
\hline $\begin{array}{l}\text { Total number of schools with Type 1 diabetic } \\
\text { children }\end{array}$ & 8 \\
\hline $\begin{array}{l}\text { Total number of schools with support services } \\
\text { being offered }\end{array}$ & 7 \\
\hline Total number of schools with diabetes policy & 1 \\
\hline Total number of schools with nurses & 2 \\
\hline Prevalence of Type 1 diabetes & $0.1 \%$ \\
\hline $\begin{array}{l}\text { Proportion of schools with children with Type 1 } \\
\text { diabetes }\end{array}$ & $38.1 \%$ \\
\hline Proportion schools with optimal support services & $33.3 \%$ \\
\hline
\end{tabular}


Table 2: Type of care being provided to Type 1 diabetic children and number of schools.

\begin{tabular}{|l|l|}
\hline Type of care service being offered & Number of schools offering the service: \\
\hline 1. Nutrition management/support & 7 \\
\hline 2. Insulin administration & 5 \\
\hline 3. Inclusion in physical activities & 3 \\
\hline 4. Blood glucose monitoring under supervision by a staff member & 5 \\
\hline 5. Provision of private space for insulin administration and glucose testing & 0 \\
\hline 6. Free access to clean and safe water and restrooms & 8 \\
\hline 7. Transport to ferry children to a health facility in case of emergency & 8 \\
\hline 8. Proper storage facilities for medication. e.g. refrigerators & 2 \\
\hline
\end{tabular}

Table 2 shows the type of care that was being provided and the number of studied schools offering the services. All the 8 schools had some form of transport to ferry the children in case of emergency. Most of the schools offered nutrition support. None of the schools provided a private room or space for insulin administration and blood glucose monitoring. Only 2 of the schools had refrigerators that could be used for keeping medication at the correct temperature during school hours.

\section{Knowledge about type 1 diabetes}

The mean knowledge score was $15.4 \pm 2.7$. The highest mark attained was 19.5 and the lowest mark attained was 11 . Half $(50 \%)$ of the schools scored above average on the knowledge test. The school representatives mentioned they had attained the knowledge of diabetes care through either caring of relatives with diabetes mellitus or fellow member of staff with diabetes but not from a formal training. Management of the child during school hours was the responsibility of the child and members of staff only stepped in during an emergency such as during an episode of hypoglycemia.

\section{Discussion}

This study focused on the assessment of diabetes care services, knowledge of staff members and the prevalence of Type 1 diabetes in public schools in Gweru urban district. We found a low prevalence rate of Type 1 diabetes in the primary schools of $0.1 \%$. The prevalence rates of Type 1 diabetes in general are said to be low worldwide accounting for between $5 \%$ and $10 \%$ of all the diabetes cases [15]. Little is known about the prevalence of Type 1 diabetes in both developed and developing countries. A recent survey in the United States of America (USA) estimated the prevalence in the USA to be $0.5 \%$ [16] whilst in Africa, different small scale studies have published the following low prevalences, Nigeria, Kano State 2.3/1000 [17], Mozambique 3.5/100,000, Sudan 9.5/100,000, and Zambia 12/100,000 [18]. However most of these studies were hospital based documenting prevalence rates from patients who would have visited the hospital for therapeutic services [19]. Prevalence of Type 1 diabetes is however estimated to be increasing by $2 \%-5 \%$ worldwide [20] and this is a cause for concern especially in light of inaccessible quality health care and the poor prevalence of support services in developing countries.

There were few schools that offered support services to the children and only a third of the studied schools were actively involved in supporting these children. The diabetes care that was being offered at studied schools was different per school. However despite the differences the results shows that only eight services were being provided. The findings also revealed that no trainings on management of Type 1 diabetes had been conducted. Some school representatives attained the knowledge of diabetes care through caring of relatives with diabetes mellitus and from some of the staff members who had diabetes. The less than optimal results obtained from the study corresponds to results from other studies that have been conducted though all in developed countries to evaluate diabetes care in primary schools [21]. In general it has been shown that diabetes care is less than optimal in schools in the developed world [21] with the absence of specific policies [22]. Such studies have not been conducted in developing countries. Even though Zimbabwe has a Schools Health Policy, specific policies are still required [22] that will ensure immediate safety, inclusion of the child in all activities, optimal academic performance and long term wellbeing. As this was a baseline, future studies can seek to standardize criteria for evaluating and defining optimal support services for the Zimbabwean context.

Though our study was restricted to public schools only, these have the majority of the student population hence we present for the first time the prevalence in public schools in the third largest city of Zimbabwe. Future studies must interview caregivers as to the Type of care they would require from the school environment and to find out if they are assisting the school with a care plan. Further research is also required to document the challenges faced by the children and also the school personnel as these are crucial for policy formulation and implementation.

Data collection was based on the assumption that the guardians of children with Type 1 diabetes would have informed the school's administration about their child's health status. This may have underestimated the prevalence rate as some parents regard their child's 
health information as private and confidential and thus may not have informed the school. Underestimation of prevalence could have also arisen from the fact that we did not assess private schools, home schooled children and those not in school. However our study had the strength that a fifth of the schools in Gweru urban were assessed. This forms an important baseline and contributes to evidence required to review and improve the generic Zimbabwe School Health Policy as well as the development of implementation guidelines.

The welfare and long-term being of diabetic children is important for the child's safety and optimal academic performance [2]. The school environment remains crucial for these children as they spend most of the time in school and imbalances between medication, food and physical activity can severely affect them. It is recommended that future studies should collect nationally representative data in order to inform policy makers. The Ministry of Health and Child Care should consider formulating specific guidelines for management of Type 1 diabetes mellitus for schools in Zimbabwe. The Ministry of Primary and Secondary Education must consider conducting trainings of school personnel and the pupils on management of Type 1 diabetes mellitus and including this topic in the school learning curriculum.

\section{Conclusion}

The results of this study show that there was a low but significant prevalence of Type 1 Diabetes in Gweru urban district. Public schools are ill prepared as there are few support services being provided for the management of Type 1 diabetes in the school environment. Parents, schools and community care teams should work together to provide school systems with information and ideas necessary to allow children with diabetes to participate fully and safely in school activities.

\section{Acknowledgements}

We would like to thank the Ministry of Primary and Secondary Education, as well as all school heads and staff members who participated in the study. We declare no conflict of interests.

\section{Ethical Considerations}

Permission to conduct the research was sought and obtained from the Medical Research Council of Zimbabwe (MRCZ), Ministry of Primary and Secondary Education, Director for Planning, Research and Statistics, Midlands Province Education Director and the Department of Food, Nutrition and Family Sciences, University of Zimbabwe. The purpose of the study was clearly explained to each and every participant. Approval from participants by signing of the consent forms before interviewing them was ensured.

\section{Authors Contribution}

Conceptualisation, review and editing- PC, Investigation and writing of first draft- MC.

\section{References}

1. Bresson D, von Herrath M (2004) Mechanisms underlying type 1 diabetes. Drug Discov Today Dis Mech 1: 321-327.

2. Persson E, Persson S, Gerdtham U-G, Carlsson KS, Swedish Childhood Diabetes Study Group (2019) Effect of type 1 diabetes on school performance in a dynamic world: New analysis exploring Swedish register data. Appl Econ 51: 2606-2622.

3. International Diabetes Federation (2019) Type 1 diabetes.

4. Motala AA, Omar MAK, Pirie FJ (2003) Epidemiology of type 1 and type 2 diabetes in Africa. J Cardiovasc Risk 10: 77-83.

5. Mutowo M, Gowda U, Mangwiro J, Lorgelly P, Owen A, et al. (2015) Prevalence of diabetes in Zimbabwe: A systematic review with meta-analysis. Int J Public Health 60: 1-11.

6. Patterson C, Guariguata L, Dahlquist G, Soltész G, Ogle G, et al. (2014) Diabetes in the young - a global view and worldwide estimates of numbers of children with type 1 diabetes. Diabetes Res Clin Pract 103: 161-175.

7. Guariguata L, Whiting DR, Hambleton I, Beagleya J, Linnenkampa U, et al. (2014) Global estimates of diabetes prevalence for 2013 and projections for 2035. Diabetes Res Clin Pract 103: 137-149.

8. Ministry of Primary and Secondary Education (2018) Zimbabwe School health Policy.

9. Melton D, Henderson J (2007) Do public schools provide optimal support for children with diabetes? Prev Chronic Dis 4: A78.

10. (2013) Census 2012, Provincial report Midlands. ZIMSTAT, Harare, Zimbabwe.

11. Ministry of Primary and Secondary Education (2018) Primary school lists.

12. Schwartz FL, Denham S, Heh V, Wapner A, Shubrook J (2010) Experiences of children and adolescents with type 1 diabetes in school: Survey of children, parents, and schools. Diabetes Spectr 23: 47-55.

13. Fitzgerald JT, Funnell MM, Anderson RM, Nwankwo R, Stansfield RB, et al. (2016) Validation of the revised brief diabetes knowledge test (DKT2). Diabetes Educ 42: 178-187.

14. Collins GS, Mughal S, Barnett AH, Fitzgerald J, Lloyd CE (2011) Modification and validation of the revised diabetes knowledge scale. Diabet Med 28: 306-310.

15. Melmed S, Auchus RJ, Goldfine AB (2019) Williams textbook of endocrinology.

16. Xu G, Liu B, Sun Y, Du Y, Snetselaar LG, et al. (2018) Prevalence of diagnosed type 1 and type 2 diabetes among US adults in 2016 and 2017: Population based study. BMJ 362: k1497.

17. Umar U (2016) Pattern of presentation of type 1 diabetic patients in Kano, Nigeria. Niger J Basic Clin Sci 13: 85.

18. Hall V, Thomsen RW, Henriksen O, Lohse N (2011) Diabetes in Sub Saharan Africa 1999-2011: Epidemiology and public health implications. A systematic review. BMC Public Health 11: 564.

19. Yvonne Buowari O (2013) Diabetes mellitus in developing countries and case series.

20. Maahs DM, West NA, Lawrence JM, Mayer-Davis EJ (2010) Epidemiology of type 1 diabetes. Endocrinol Metab Clin North Am 39: 481-497.

21. Lange K, Jackson C, Deeb L (2009) Diabetes care in schools--the disturbing facts. Pediatr Diabetes 13: 28-36.

22. Miranda Velasco MJ, Solís G, Martín E (2015) Global standards and local policies for school diabetes care. Health 7: 1642-1650. 